\title{
Publisher Correction: HP1 shapes embryonic genome architecture
}

Anke Sparmann

Correction to: Nature Structural \& Molecular Biology https://doi.org/10.1038/s41594-021-00594-6, published online 10 May 2021.

In the version of this article initially published, the article that is the subject of the News \& Views was not cited in the main text. The citation should have been present in the first paragraph as follows: "Iovino, Giorgetti and colleagues (Nature https://doi.org/10.1038/ s41586-021-03460-z (2021)) now identify...." The error has been corrected in the HTML and PDF versions of the article.

Published online: 18 May 2021

https://doi.org/10.1038/s41594-021-00612-7

๑) Springer Nature America, Inc. 2021 